\title{
A method for measuring the absolute sensitivity of positron emission tomographic scanners
}

Dale L. Bailey ${ }^{1,2}$, Terry Jones ${ }^{1}$, and Terry J. Spinks ${ }^{1}$

${ }^{1}$ MRC Cyclotron Unit, Hammersmith Hospital, London, UK

${ }^{2}$ Department of Nuclear Medicine, Royal Prince Alfred Hospital, Sydney, Australia

Eur J Nucl Med (1991) 18:374-379

Equations 1 (page 375) and 2 (page 376) should have read as follows:

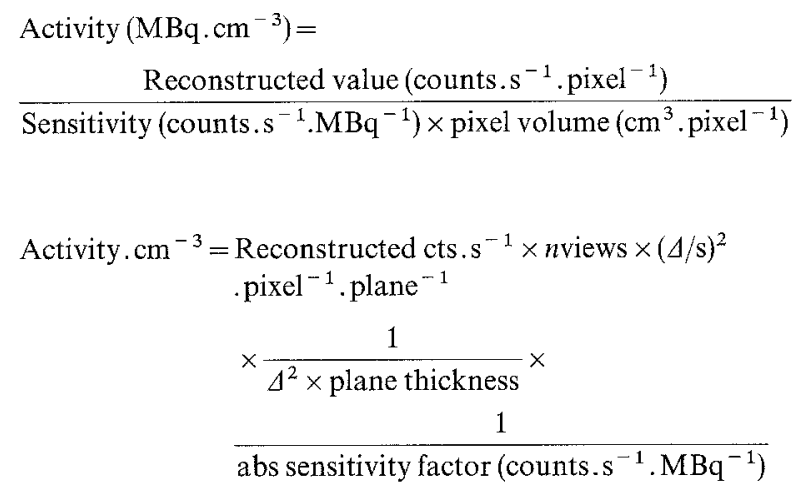

$$
\begin{aligned}
\text { Activity } . \mathrm{cm}^{-3}= & \text { Reconstructed cts } \cdot \mathrm{s}^{-1} \times n \text { views } \times(\Delta / \mathrm{s})^{2} \\
& \text { pixel }{ }^{-1} \cdot \text { plane }{ }^{-1} \\
& \times \frac{1}{\Delta^{2} \times \text { plane thickness }} \times \\
& \frac{1}{\text { abs sensitivity factor (counts. } \left.{ }^{-1} \cdot \mathrm{MBq}^{-1}\right)}
\end{aligned}
$$

